\title{
Estimating leopard density across the highly modified human-dominated landscape of the Western Cape, South Africa
}

\author{
Carolyn H. Devens, Matt W. Haymard, Thulani Tshabalala, Amy Dickman \\ Jeannine S. McManus, Bool Smuts and Michael J. Somers
}

\begin{abstract}
Apex predators play a critical role in maintaining the health of ecosystems but are highly susceptible to habitat degradation and loss caused by land-use changes, and to anthropogenic mortality. The leopard Panthera pardus is the last free-roaming large carnivore in the Western Cape province, South Africa. During 2011-2015, we carried out a camera-trap survey across three regions covering c. $30,000 \mathrm{~km}^{2}$ of the Western Cape. Our survey comprised 151 camera sites sampling nearly 14,000 camera-trap nights, resulting in the identification of 71 individuals. We used two spatially explicit capture-recapture methods ( $R$ programmes secr and SPACECAP) to provide a comprehensive density analysis capable of incorporating environmental and anthropogenic factors. Leopard density was estimated to be 0.35 and 1.18 leopards $/ 100 \mathrm{~km}^{2}$, using secr and SPACECAP, respectively. Leopard population size was predicted to be 102-345 individuals for our three study regions. With these estimates and the predicted available leopard habitat for the province, we extrapolated that the Western Cape supports an estimated 175-588 individuals. Providing a comprehensive baseline population density estimate is critical to understanding population dynamics across a mixed landscape and helping to determine the most appropriate conservation actions. Spatially explicit capture-recapture methods are unbiased by edge effects and superior to traditional capture-markrecapture methods when estimating animal densities. We therefore recommend further utilization of robust spatial methods as they continue to be advanced.
\end{abstract}

Carolyn H. Devens* (Corresponding author, (1) orcid.org/0000-0002-75390969), Matt W. Hayward $\dagger$ and Michael J. Somers (DiD orcid.org/0000-00025836-8823) Mammal Research Institute, Department of Zoology and Entomology, University of Pretoria, Pretoria, South Africa

E-mail chdevens@gmail.com

Thulani Tshabalala $\ddagger$ Jeannine S. McManus $§$ and Bool Smuts $§$ Research Department, Landmark Foundation, Riversdale, South Africa

Amy DickMan WildCRU, Oxford University, Abingdon, UK

*Also at: Research Department, Landmark Foundation, Riversdale, South Africa $\dagger$ Also at: School of Environmental and Life Sciences, University of Newcastle, Callaghan, Australia

¥Also at: School of Agricultural, Earth and Environmental Sciences, University of KwaZulu-Natal, Durban, South Africa

$\S$ Also at: Department of Biodiversity and Conservation Biology, University of the Western Cape, Cape Town, South Africa

IAlso at: Centre for Invasion Biology, University of Pretoria, Pretoria, South Africa

Received 1 December 2017. Revision requested 19 March 2018.

Accepted 30 November 2018. First published online 30 September 2019.
Keywords Camera trapping, carnivore conservation, leopard, Panthera pardus, secr, SPACECAP, spatially explicit capture-recapture

Supplementary material for this article is available at https://doi.org/10.1017/So030605318001473

\section{Introduction}

The exponential growth of the human population is I threatening all levels of biodiversity, including large carnivores, with $77 \%$ of species' populations experiencing continuing declines (Estes et al., 2011; Ripple et al., 2014). Large carnivores are particularly at risk of extinction because of their small population sizes, slow reproductive rates, complex social structures and requirement for large and contiguous habitats with sufficient prey (Cardillo et al., 2004; Ripple et al., 2014). These characteristics, and their vulnerability to negative interactions with humans, have driven declines of some of the most wide-ranging carnivores (Cardillo et al., 2004; Ray et al., 2005; Swanepoel et al., 2013; Wolf \& Ripple, 2017).

Although the leopard is considered the most adaptable large carnivore (Ripple et al., 2014), range declines of $63-75 \%$ globally, $48-67 \%$ in Africa and $28-51 \%$ in southern Africa indicate that leopard populations are not as resilient to anthropogenic influences as previously believed (Jacobson et al., 2016). Major anthropogenic threats to leopards include ongoing habitat loss and fragmentation (Harcourt et al., 2001; Crooks, 2002; Swanepoel et al., 2015), depletion of prey resources (Woodroffe, 2000; Karanth \& Chellam, 2009), unsustainable hunting levels (Woodroffe, 2000; Harcourt et al., 2001) and direct persecution by people (Harcourt et al., 2001; Treves \& Karanth, 2003; Treves et al., 2004; Treves \& Naughton-Treves, 2005; McManus et al., 2014; Swanepoel et al., 2015). Increasing human population density and loss of habitat increase the likelihood of resource competition with people, often resulting in human-carnivore conflict (Woodroffe, 2000; Cardillo et al., 2004). Persecution often includes indiscriminate use of lethal methods to manage livestock depredation by carnivores (e.g. snares, poisoned carcasses, gin traps (leg-hold traps), gun traps, live trapping) and targeted (often retaliatory) hunting (McManus et al., 2014). 
Estimating a species' density across various types of land cover (i.e. habitat and vegetation type) and land uses (i.e. residential/urban land, cultivated land, commercial and recreational land and areas protected for conservation) can help determine how population numbers are affected by landscape features. Density estimates are not equally robust, and under- or overestimating populations can have substantial implications for conservation management and policy (Foster \& Harmsen, 2012; Hayward et al., 2015). For example, Soisalo \& Cavalcanti (2006) demonstrated how overestimating jaguar Panthera onca populations by five individuals per $100 \mathrm{~km}^{2}$ inflated the overall population estimate by 7,000 individuals across their $140,000 \mathrm{~km}^{2}$ study region. Density estimation also depends upon data quality, with a large enough sample size and capture probability for the chosen analysis method (Foster \& Harmsen, 2012).

Conservationists and ecologists constantly seek to improve the methodology for estimating animal population abundances and densities (Griffiths \& van Schaik, 1993; Karanth \& Nichols, 1998; Karanth \& Nichols, 2000). The use of camera traps and photo capture-recapture analysis is a common and effective non-invasive practice for obtaining data on wildlife population dynamics, particularly of rare or elusive species (Foster \& Harmsen, 2012). Leopards, like many other large felids, are challenging to monitor because of their large home ranges, low population density and primarily solitary and elusive nature (Karanth \& Nichols, 2000; Treves \& Karanth, 2003). Global population estimates across the leopard's vast geographical distribution do not account for the health and sustainability of smaller, isolated regional metapopulations across a variety of habitat types, countries and levels of human landscape modification and pressure.

Camera-trap surveys have become an important data collection method for population and density studies because they are non-invasive, practical and affordable (Karanth, 1995; Karanth \& Nichols, 1998; Foster \& Harmsen, 2012). The capture-recapture method relies on individuals being identifiable (Karanth, 1995; Silver et al., 2004) and has been the predominant approach used in felid density studies.

More recently, spatial capture-recapture or spatially explicit capture-recapture methods have become popular because they provide comprehensive analyses that can incorporate environmental and anthropogenic factors when estimating animal densities. These methods enable density analyses to include spatio-temporal data from capture histories, providing direct estimates of population density that remain unbiased by edge effects (Chase Grey et al., 2013). By allowing for flexibility in individual heterogeneity with the consideration of capture probability relative to trap location, spatial covariates such as habitat, and intrinsic factors such as sex and age (Foster \& Harmsen, 2012; Efford \&
Fewster, 2013), spatially explicit capture-recapture models are becoming increasingly robust and comprehensive.

These statistical and methodological advances provide multiple options that can be applied to specific study questions while making population density estimates increasingly reliable. Inaccurate density estimates can lead to biased population estimates, with serious implications for conservation management (Soisalo \& Cavalcanti, 2006).

The estimation of a baseline population density for leopards in South Africa's Western Cape province is fundamental for understanding how this regionally important population responds to landscape-scale threats and changes. By estimating densities across landscapes of varying resource availability and threats, we can examine drivers of regional density variation and improve conservation management for disjunct populations.

\section{Study area}

This study covers c. $30,000 \mathrm{~km}^{2}$ in three areas (Langeberg, Overberg and Garden Route) in the Western Cape, South Africa (Fig. 1). The topography varies from the Cape Fold Mountain peaks with an altitude of $>1,600 \mathrm{~m}$ that extend $1,000 \mathrm{~km}$ east to west, to coastal and low-lying valleys at $<500 \mathrm{~m}$ altitude (Thamm \& Johnson, 2006). Biomes included in our study are Thicket, Afro-temperate forest (Forest), Sandstone fynbos (Fynbos), Nama-Karoo, Succulent-Karoo and Savanna (Mucina \& Rutherford, 2006).

In the Langeberg we deployed camera traps in the greater Riversdale/Heidelberg area on the southern slopes of Langeberg Mountain Range, in the greater Greyton area on the southern slope of Riviersonderend Mountain Range and in the Robertson Wine Valley (Breede River Valley) situated between the Langeberg and Riviersonderend Mountain Ranges. In the Overberg we surveyed the greater Hermanus area to the west, the greater Cape Agulhas and Arniston areas to the south along the coast, and the greater De Hoop Nature Reserve area to the eastern extent of the surveyed region. Along the Garden Route we surveyed temperate forest along the southern slopes of the Outeniqua and Tsitsikamma Mountains from George in the west to the Bloukrans River in Plettenberg Bay in the east.

\section{Methods}

\section{Camera-trap surveys}

We undertook seven large-scale camera-trap surveys during June 2011-March 2015, focusing on likely presence of leopards inside and outside protected areas and across different agricultural land-use zones (livestock, crops, forestry). We used Cuddeback Attack IR (Cuddeback, Green Bay, USA) digital infrared cameras and selected camera-trap locations 


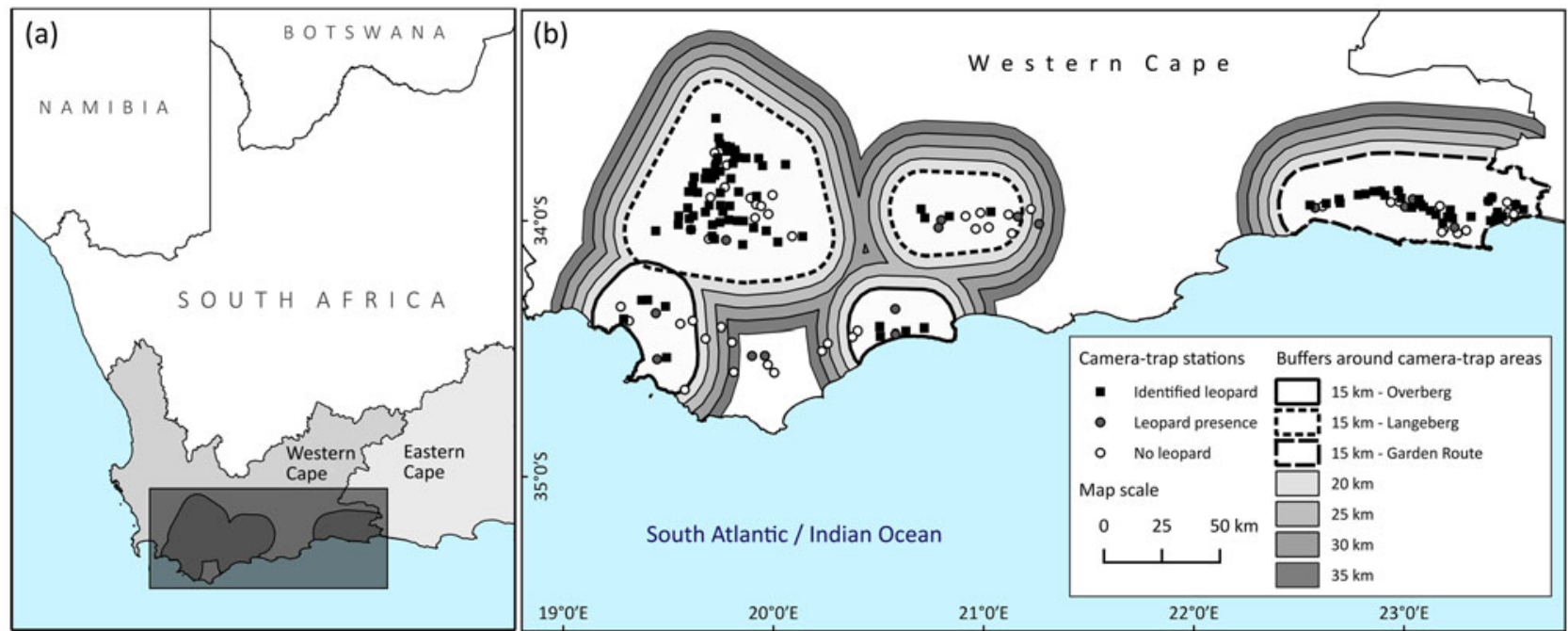

FIG. 1 (a) Location of the study areas in the Western Cape province, South Africa. (b) Camera-trap surveys conducted across the Langeberg $\left(19,063 \mathrm{~km}^{2}\right)$, Garden Route $\left(6,680 \mathrm{~km}^{2}\right)$ and Overberg $\left(7,910 \mathrm{~km}^{2}\right)$ areas. Data from camera stations with identified leopards were analysed with programmes SPACECAP and secr with various buffers.

based on the highest likelihood of leopard activity as determined by physical evidence (scat, spoor and territorial scent and scratch markings on trees), as well as habitat type and topography (Karanth \& Nichols, 2000). At each cameratrap station, we positioned two cameras to capture both flanks of a passing leopard. The stations were placed 3-5 $\mathrm{km}$ apart to achieve even coverage of the sampling area and camera stations remained active for a minimum of 3 months to ensure maximum likelihood of leopard activity being captured without violating the closed population assumption (Karanth \& Nichols, 1998; Devens et al., 2018).

\section{Capture-recapture identification}

Individual leopards can be identified from clear photographs of both flanks by their unique rosette markings. Identification from single flank photos is possible, but needs to be based upon the observation of characteristics such as the animal's overall size, neck girth, injuries or scars. Although such characteristics may be useful, incorrectly identified individuals could bias density estimates, resulting in overestimation of the population if flank photos of the same animal were erroneously assigned to two individuals. We therefore only utilized double flank capture events for identification.

\section{Data analysis}

Spatially explicit capture-recapture methods for density analyses are more comprehensive and reliable than traditional capture-recapture analyses (Borchers \& Efford, 2008; Kalle et al., 2011; Gopalaswamy et al., 2012; Chase Grey et al., 2013; Thapa et al., 2014) and produce lower density estimates than non-spatial methods (Obbard et al., 2010; Gerber et al., 2012; Gopalaswamy et al., 2012; Noss et al., 2012; Braczkowski et al., 2016). We calculated density estimates using two spatially explicit capture-recapture methods within the programming environment $R$ 3.4.0 ( $\mathrm{R}$ Development Core Team, 2017): (1) the maximum likelihood based estimator programme secr 2.10.3 (Efford et al., 2009; Efford, 2011, 2016), which is a more robust version of programme DENSITY (Efford, 2011), and (2) the Bayesian estimator programme SPACECAP 1.1.o (Gopalaswamy et al., 2012). Previous studies have applied these two programmes to compare density estimates (Kalle et al., 2011; Thapa et al., 2014) and to compare results of spatially explicit capture-recapture with non-spatial methods (Noss et al., 2012; Braczkowski et al., 2016). We used these programmes for comparison of two spatially explicit capture-recapture methods and to determine the most robust and inclusive density estimate range for each study region.

For the analysis with secr we categorized camera traps as count detectors, which allows repeat detections. Count data can result from devices such as automatic camera traps. Count detectors record the presence of an animal at a trap location without restricting movement and allow $>1$ detection of an individual at a particular site on any occasion. The secr.fit function was run for each regional survey phase using models of time $(g \circ \sim T)$ and behavioural response $(g \circ \sim b)$, as well as buffers of $15,20,25,30$ and $35 \mathrm{~km}$ surrounding the minimal convex polygon around camera stations in each camera-trapping area. These buffers ensured inclusion of all leopard home ranges within reach of camera traps (Kalle et al., 2011) and made density estimation more reliable by determining the point at which the density estimate stabilized (Kalle et al., 2011; Chase Grey et al., 2013). 
SPACECAP was used to estimate abundance and density using spatially-explicit capture-recapture models to derive spatial Bayesian estimates with trap response. A grid of equally spaced points $1 \mathrm{~km}$ apart was generated in QGIS 2.8 (QGIS Development Team, 2013) and clipped to the surveyed area containing the camera trap array combined with an extended surrounding area, known as the state-space, at distances of 15, 20, 25, 30 and $35 \mathrm{~km}$. These points represent all potential home range centres of all leopards within the survey. The potential home range centres file included the geographical coordinates and habitat suitability of each of these points within the state-space. We determined habitat suitability using Maxent 3.3.3 (Phillips et al., 2006; Phillips et al., 2017) model output comprising environmental variables, including eight WorldClim bioclimatic variables obtained from WorldClim website (Hijmans et al., 2005), human footprint index (WCS \& CIESIN, 2005), altitude, anthropogenic biomes (Ellis \& Ramankutty, 2008), Globcover 2009 (FAO, 2012), South African National Bio-diversity Institute ecosystem status of vegetation types (Rouget et al., 2004), and a subset of location data obtained from two leopards resident in the area that were equipped with GPS collars. We used the Natural Breaks function (Jenks, 1967) in ArcMap 10.3.1 to code the model output as either o (not suitable $=0-0.189171$ ) or 1 (suitable $=0.189172-0.775)$. The habitat suitability generated in this way (Jenks method) was recorded for each point and a home range centre input file was generated for each area's buffer distances (Fig. 2).

We ran SPACECAP with a $1 \mathrm{~km}^{2}$ pixel area, and set the model definitions to 'Trap response present', 'Spatial Capture-Recapture', 'half normal' detection function and the capture encounters 'Bernoulli's process'. The 'Trap response present' option implements a 'trap-specific' behavioural response in which the probability of capture at a specific trap increases (or decreases) after the initial capture. The
'Spatial Capture-Recapture' option runs a spatially explicit capture-recapture analysis. The Markov-Chain Monte Carlo settings varied between study areas and buffers. Markov-Chain Monte Carlo iterations were set between 60,000 and 100,000 with a burn-in period between 10,000 and 65,000 iterations and a thinning rate of 1 . The data augmentation numbers were c. 20-40 times the number of animals identified in each regional survey and varied between 170 and 1,500. We assessed chain convergence with the Geweke diagnostic test produced within the SPACECAP output in the form of $z$-score values. $Z$-scores between -1.6 and +1.6 implied adequate convergence and confirmed that the Markov-Chain Monte Carlo analysis was run with a sufficiently long burn-in period. The SPACECAP output also produces a Bayesian P-value to provide additional assessment of the model fit where P-values close to o or 1 imply that the model is inadequate. The adequacy of the data augmentation number can be checked in the 'density plot for psi' and 'density plot for $\mathrm{N}$ ' files included within the output files. All densities obtained with SPACECAP produced $z$-scores that achieved convergence, as well as sufficient model fit and data augmentation number. The output also included pixel-specific density estimates (animals per $\mathrm{km}^{2}$ ), which we used to create a pixel density map of the study areas and compare leopard densities across various land covers and uses to illustrate relationship with anthropogenic factors.

\section{Results}

\section{Camera-trap data and sampling effort}

The total sampling effort for the Overberg (November 2011March 2012) was 2,880 camera-trap nights across a total of 32 camera-trap locations (64 cameras). This yielded 118 leopard photographs (captures), with eight individuals

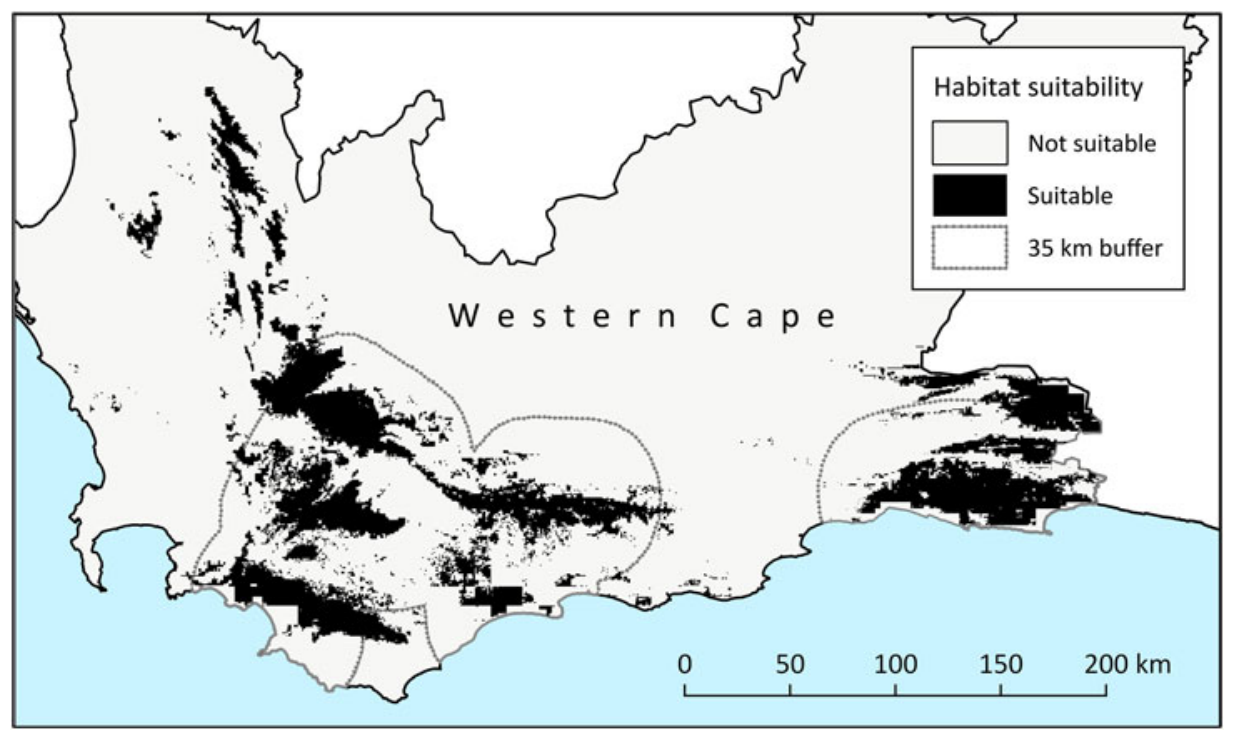

FIg. 2 Maxent probability distribution model of leopard habitat suitability in the Western Cape and considering this study's $35 \mathrm{~km}$ buffers around camera-trap areas. Distribution model is reclassified with Natural Breaks function. 
identified in 40 of them. These individuals were detected at nine of the 32 camera-trap sites (Table 1).

The total sampling effort for the two phases of the Langeberg survey (April 2012-December 2012) consisted of 9,480 camera-trap nights across a total of 79 camera-trap locations (158 cameras). This yielded 454 leopard captures, from which 42 individual leopards were identified in 250 photographs, and these individuals were detected at 58 of the 79 camera-trap sites (Table 1).

The total sampling effort for the three phases of the Garden Route survey area (May 2013-December 2014) was 3,600 camera-trap nights across a total of 40 camera-trap locations (8o cameras). This yielded 142 leopard captures, of which 21 individual leopards were identified in 86 photographs, and these individuals were detected at 33 of the 40 camera-trap sites (Table 1). The total sampling effort was 13,590 camera-trap nights across 151 camera-trap locations (302 cameras), with 714 leopard captures and 71 identified individuals (Table 1).

\section{Density estimates}

The spatially explicit capture-recapture density estimates varied by region and between regional phases, and estimates from secr were lower than those from SPACECAP. The effect of using various buffers within the two programmes, particularly SPACECAP, demonstrated the sensitivity to buffer width and data augmentation size (Kalle et al., 2011). We calculated mean density estimates from stabilized buffer values to ensure the study area was large enough to avoid capturing any individuals residing outside the buffered region during the survey.

In the Overberg, secr density estimates stabilized at 0.17 leopards/10o km² (CI $0.06-0.48$ ). Both phases in the Langeberg had density estimates that were stable across all five buffers with a phase one density estimate of 0.29 leopards $/ 100 \mathrm{~km}^{2}$ (CI $0.2-0.41$ ) and a phase two estimate of 0.7 leopards $/ 100 \mathrm{~km}^{2}$ (CI 0.57-1.76). The Garden Route's first phase had an estimated density of 0.5 leopards $/ 100 \mathrm{~km}^{2}$ (CI 0.19-1.32) with densities stable across all buffers, whereas phase two had an estimated density of 0.34 leopards $/ 100 \mathrm{~km}^{2}$ (CI $0.18-0.63$ ) and phase three produced a density estimate of 0.29 leopards $/ 100 \mathrm{~km}^{2}$ (CI 0.13-0.67; Table 2). We calculated the mean density for multi-phase study areas resulting in 0.17 leopards $/ 100 \mathrm{~km}^{2}$ in the Overberg, compared to 0.5 leopards $/ 100 \mathrm{~km}^{2}$ (CI $0.39-1.09$ ) in the Langeberg and 0.38 leopards $/ 100 \mathrm{~km}^{2}$ (CI $0.17-0.87$ ) along the Garden Route. The highest estimated density was Langeberg's phase two with 0.7 leopards $/ 100 \mathrm{~km}^{2}$, and the lowest was 0.17 leopards $/ 100 \mathrm{~km}^{2}$ in the Overberg (Table 2).

SPACECAP produced an Overberg density estimate of 0.69 leopards/10o km² (CI o.39-1.28), Langeberg phase one and two density estimates of 1.67 (CI 1.21-2.18) and 2.11 (CI 1.46-2.82) leopards/100 $\mathrm{km}^{2}$, respectively, and Garden

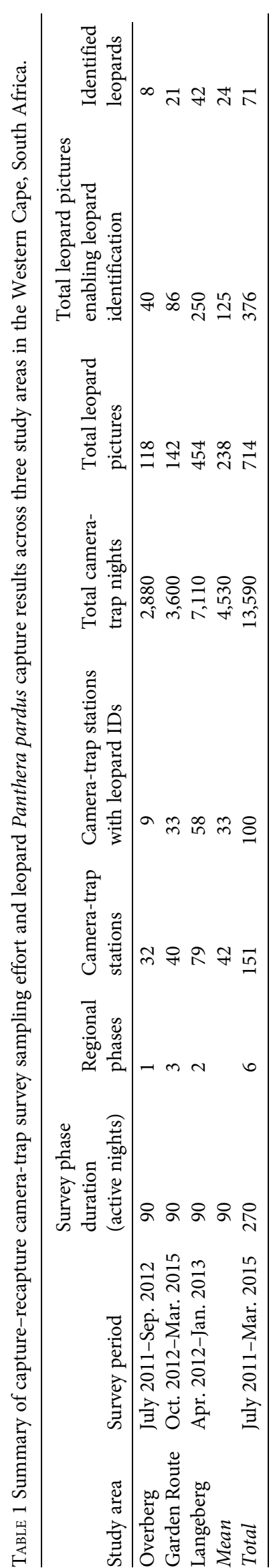


TABLE 2 Density estimates from programmes secr and SPACECAP, with standard error (SE), standard deviation (SD), 95\% confidence intervals (CI), range of buffers that achieved mean density estimate stabilization, area of regional $35 \mathrm{~km}$ buffer, number of leopards estimated within the surveyed area, and the Bayesian P-value for model fit.

\begin{tabular}{|c|c|c|c|c|c|c|c|c|}
\hline & \multicolumn{2}{|l|}{$\begin{array}{l}\text { Density estimate } \\
\left(\text { leopards } / 100 \mathrm{~km}^{2} \text { ) }\right.\end{array}$} & \multicolumn{2}{|c|}{$\begin{array}{l}\text { Buffer range of means' } \\
\text { stabilization }(\mathrm{km})\end{array}$} & \multirow[b]{2}{*}{$35 \mathrm{~km}$ buffer area $\left(\mathrm{km}^{2}\right)$} & \multicolumn{2}{|c|}{ Estimated no. of leopards } & \multirow{2}{*}{$\begin{array}{l}\text { P-value } \\
\text { SPACECAP }\end{array}$} \\
\hline & $\begin{array}{l}\text { secr } \\
\text { mean } \pm \text { SE }(95 \% \text { CI })\end{array}$ & $\begin{array}{l}\text { SPACECAP } \\
\text { mean } \pm \mathrm{SD}(95 \% \mathrm{CI})\end{array}$ & secr & SPACECAP & & $\begin{array}{l}\text { secr } \\
(95 \% \mathrm{CI})\end{array}$ & $\begin{array}{l}\text { SPACECAP } \\
(95 \% \mathrm{CI})\end{array}$ & \\
\hline \multicolumn{9}{|l|}{ Langeberg } \\
\hline Phase 1 & $0.29 \pm 0.05(0.20-0.41)$ & $1.67 \pm 0.26(1.21-2.18)$ & $15-35$ & $15-30$ & & & & 0.86 \\
\hline Phase 2 & $0.70 \pm 0.15(0.57-1.76)$ & $2.11 \pm 0.35(1.46-2.82)$ & $15-35$ & $25-35$ & & & & 0.55 \\
\hline Area mean & $0.50 \pm 0.10(0.39-1.09)$ & $1.89 \pm 0.30(0.89-2.50)$ & & & $19,063.42$ & $\begin{array}{l}93.41 \\
(74.35-205.88)\end{array}$ & $\begin{array}{l}360.30 \\
(169.70-476.60)\end{array}$ & 0.71 \\
\hline \multicolumn{9}{|c|}{ Garden Route } \\
\hline Phase 1 & $0.50 \pm 0.26(0.19-1.32)$ & $1.44 \pm 0.58(0.55-2.54)$ & $15-35$ & $20-30$ & & & & 0.47 \\
\hline Phase 2 & $0.34 \pm 0.11(0.18-0.63)$ & $0.92 \pm 0.16(0.65-1.22)$ & $25-35$ & $20-35$ & & & & 0.73 \\
\hline Phase 3 & $0.29 \pm 0.13(0.13-0.67)$ & $0.51 \pm 0.10(0.36-0.70)$ & $20-35$ & $15-35$ & & & & 0.60 \\
\hline Area mean & $0.38 \pm 0.17(0.17-0.87)$ & $0.96 \pm 0.28(0.52-1.49)$ & & & $6,680.34$ & $\begin{array}{l}25.39 \\
(11.36-58.12)\end{array}$ & $\begin{array}{l}64.13 \\
(34.74-99.54)\end{array}$ & 0.60 \\
\hline \multicolumn{9}{|l|}{ Overberg } \\
\hline Phase 1 & $0.17 \pm 0.10(0.06-0.48)$ & $0.69 \pm 0.30(0.39-1.28)$ & $30-35$ & $25-35$ & $7,910.04$ & $\begin{array}{l}13.45 \\
(4.75-37.97)\end{array}$ & $\begin{array}{l}54.58 \\
(30.85-101.25)\end{array}$ & 0.63 \\
\hline Overall mean & $0.35 \pm 0.12(0.21-0.81)$ & $1.18 \pm 0.29(0.60-1.76)$ & & & $11,217.93$ & $\begin{array}{l}44.08 \\
(30.15-100.66)\end{array}$ & $\begin{array}{l}159.67 \\
(78.42-225.79)\end{array}$ & 0.65 \\
\hline \multicolumn{5}{|c|}{ Total area without overlap ${ }^{1}$} & $29,258.43$ & $\begin{array}{l}132.25 \\
(90.46-301.97)\end{array}$ & $\begin{array}{l}479.01 \\
(235.25-677.38)\end{array}$ & \\
\hline
\end{tabular}

${ }^{1}$ The area total is without $35 \mathrm{~km}$ buffer land overlap between survey areas. 
Route phase one, two and three of 1.44 leopards $/ 100 \mathrm{~km}^{2}$ (CI $0.55-2.54$ ), 0.92 leopards $/ 100 \mathrm{~km}^{2}$ (CI 0.16-1.22) and 0.51 leopards/10o km² (CI $0.36-0.7$ ), respectively. Again, we calculated the mean density for multi-phase areas; the Overberg was 0.69 leopards $/ 100 \mathrm{~km}^{2}$, compared to 1.89 leopards/100 $\mathrm{km}^{2}$ (CI $\left.0.89-2.5\right)$ in the Langeberg and 0.96 leopards/100 $\mathrm{km}^{2}$ (CI 0.52-1.49) along the Garden Route (Table 2).
Analysis with secr and SPACECAP resulted in an overall estimated leopard density of 0.35 leopards $/ 100 \mathrm{~km}^{2}$ (CI $0.21-0.81$ ) and 1.18 leopards/10o km² (CI $0.60-1.76)$ respectively. The output from SPACECAP includes a pixel density file, which we converted into a fine-scale map using QGIS, showing the variation of estimated animal densities across each of the potential home range centres
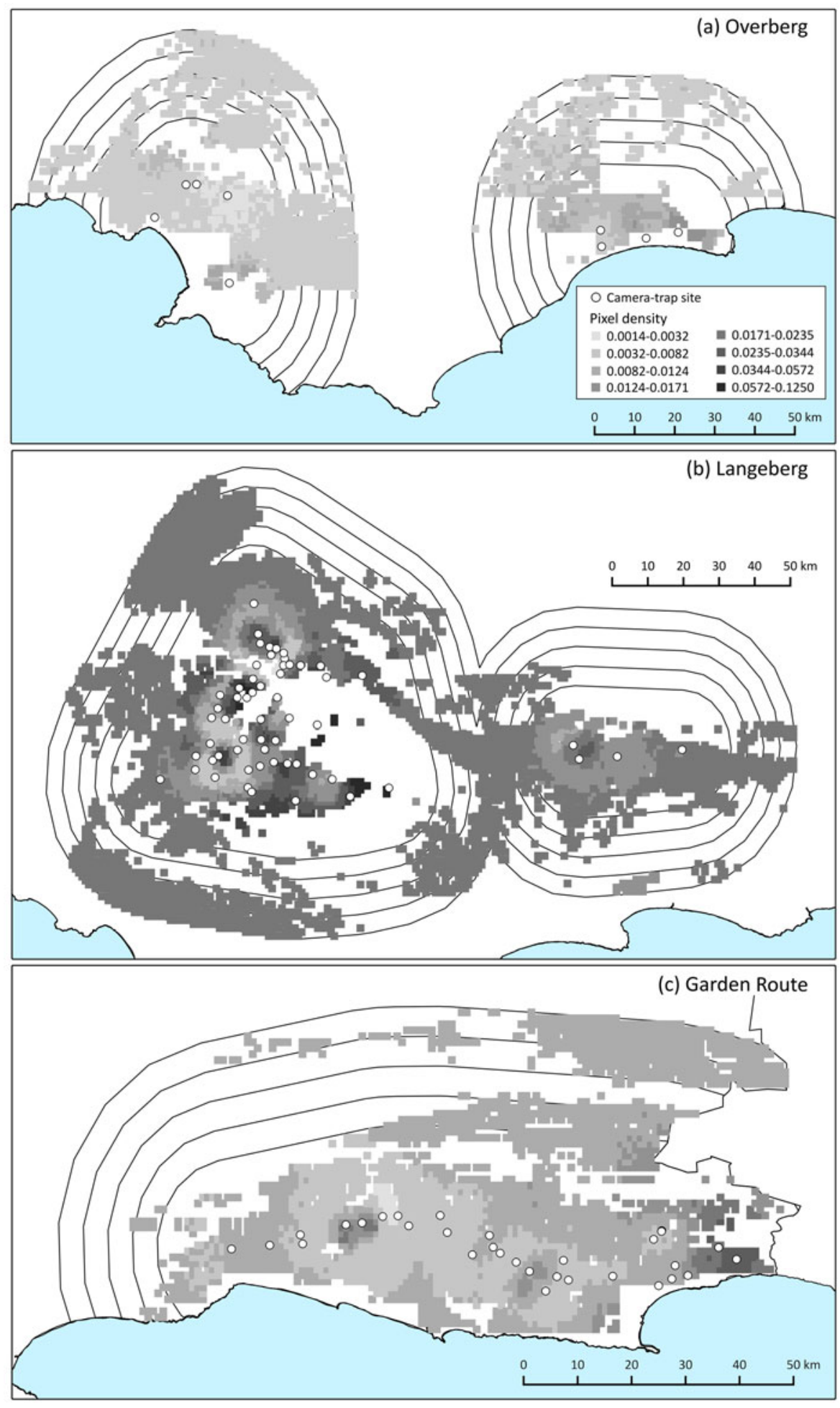

FIG. 3 Pixelated $\left(1 \mathrm{~km}^{2}\right)$ SPACECAP leopard density maps showing the (a) Overberg, (b) Langeberg and (c) Garden Route study areas. Camera-trap sites shown are sites with individually identified leopards. 


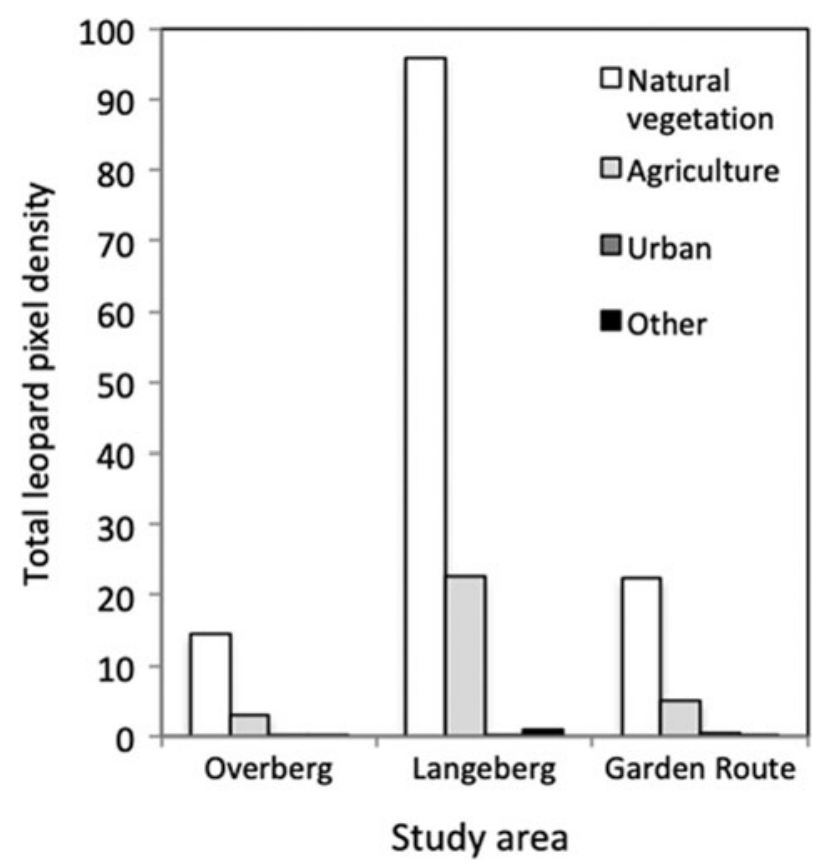

FIG. 4 Sum of SPACECAP leopard pixel density estimates (leopards $/ \mathrm{km}^{2}$ ) for different land-cover types in the Western Cape study areas. 'Agriculture' includes cultivated commercial fields, orchards and plantations, 'urban' includes residential and urban commercial land, and 'other' includes dams, roads and railways.

(Fig. 3). Using these pixel density values, we also created study area graphs depicting the sum of pixel densities across land cover categories (CapeNature, 2014) and protected areas (Department of Environmental Affairs, 2017; Fig. 4).

\section{Estimated population numbers}

Combining this study's total area with each region's $35 \mathrm{~km}$ buffer width (Garden Route 6,680.34 km²; Overberg $7,910.04 \mathrm{~km}^{2}$; Langeberg $19,063.42 \mathrm{~km}^{2}$ ) with the regional secr mean density estimates results in an estimate of 25 leopards (CI 11.4-58.1) in the Garden Route, 13 leopards (CI 4.7-38.0) in the Overberg and 93 leopards (CI 74.3-205.9) in the Langeberg (Table 2). The total estimate for all areas combined was 132 leopards (CI 90.4-302.0; Table 2). In comparison, combining the total non-overlapping area of all three study area' $35 \mathrm{~km}$ buffers $\left(29,258.43 \mathrm{~km}^{2}\right)$ with the overall secr mean density produces a population estimate of 102 leopards (CI 61.4-237.0) in the total study area (Table 3).

With the regional SPACECAP mean density estimates there would be c. 64 leopards (CI 34.7-99.5) in the Garden Route, 55 leopards (CI 30.8-101.2) in the Overberg and 360 leopards (CI 169.7-476.6) in the Langeberg (Table 2), yielding a total estimate of 479 leopards (CI 235.3-677.4; Table 2). Comparatively, using the total area of all three regions' $35 \mathrm{~km}$ buffers (without overlap) and the overall SPACECAP mean density provides a population estimate of 345 leopards (CI 175.6-515.0) for the entire study area (Table 3).

Our study area of $29,258.43 \mathrm{~km}^{2}$ comprises $23 \%$ of the Western Cape's total area $\left(129,460 \mathrm{~km}^{2}\right)$. To provide a population outlook at the provincial level we extrapolated an ecologically useful Western Cape abundance estimate using our secr and SPACECAP mean density estimates and Swanepoel et al.'s (2013) estimated $49,850 \mathrm{~km}^{2}$ of remaining suitable leopard habitat in Western Cape (38\% of the province). This suggests that the entire Western Cape could harbour as few as 175 (CI 104.7-403.8) and as many as 588 (CI 299.1-877.4) leopards (Table 3).

\section{Discussion}

This study covered c. $30,000 \mathrm{~km}^{2}$ and is one of the most extensive leopard camera-trap density estimate surveys conducted in the Western Cape province of South Africa. We compared the use of two spatially explicit capture-recapture methods for a regionally imperilled disjunct leopard population. Our comprehensive density analysis investigated leopard persistence in a predominately human-modified and privately-owned landscape with varying degrees of conflict and persecution.

It is important to reiterate that our study area incorporates variation across vegetation types, landscape topography and degree of landscape modification and fragmentation. Because of its highly cultivated agricultural landscape (mainly grain production, as well as livestock farming), the Overberg is commonly considered as the breadbasket of the Cape. The Langeberg's Breede River Valley is encircled by the Cape Fold Mountain ranges and is dominated by fynbos, vineyards and orchards, whereas the Garden Route is a long stretch of the south-western coast situated between mountains to the north and the Indian Ocean to the south, which harbours a unique mixture of fynbos, indigenous

TABLE 3 Comparison of estimated population size of leopards using the total area within this study's $35 \mathrm{~km}$ buffer distance (without regional survey overlap) and Swanepoel et al.'s (2013) estimate for suitable leopard habitat in the Western Cape.

\begin{tabular}{lll}
\hline Area & secr $\left(0.35\right.$ leopards $\left./ 100 \mathrm{~km}^{2}\right)$ & SPACECAP $\left(1.18\right.$ leopards $\left./ 100 \mathrm{~km}{ }^{2}\right)$ \\
\hline Total buffered area of this study $\left(29,258.43 \mathrm{~km}^{2}\right)$ & $102.4(95 \%$ CI $61.4-237.0)$ & $345.3(95 \%$ CI $175.6-515.0)$ \\
Suitable leopard habitat in the Western Cape $\left(49,850 \mathrm{~km}^{2} ;\right.$ & $174.5(95 \%$ CI 104.7-403.8) & $588.2(95 \%$ CI 299.1-877.4) \\
$\quad$ Swanepoel et al., 2013) & & \\
\hline
\end{tabular}




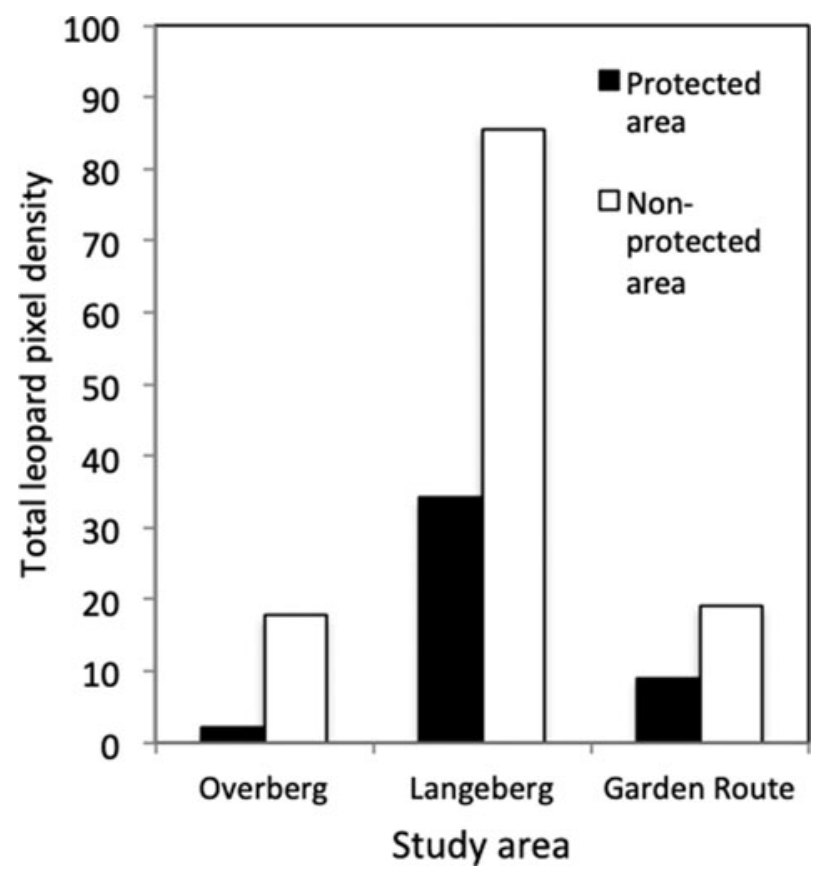

FIG. 5 Sum of SPACECAP leopard pixel density estimates (leopards $/ \mathrm{km}^{2}$ ) for suitable leopard habitat within protected and non-protected areas for each study area in the Western Cape.

temperate forest and forestry plantations. The agricultural land in all three areas is utilized by leopards, as evidenced by capture and recapture locations and suitable habitat extending beyond natural vegetation (Fig. 4) and protected area boundaries (Fig. 5). None of our identified territorial adult leopards remained strictly within protected areas, and most did not utilize any protected land within their home range. Although protected areas play a crucial role in the conservation of natural landscapes, they do not encompass the entirety of remaining natural vegetation or existing leopard habitat. In the Western Cape $79 \%$ of conservation areas contain suitable leopard habitat but only $30 \%$ of leopard habitat occurs within conservation areas (Swanepoel et al., 2013).

These findings, together with estimated leopard densities within highly modified, cultivated and non-protected land (Figs 4 \& 5), suggest that non-protected, mostly privately owned land plays an important role in sustaining the Western Cape leopard population. Both spatially explicit capture-recapture methods suggest that the Langeberg winelands region supports the highest leopard density and the Overberg's agricultural landscape the lowest. The sum of each study area's pixel densities is consistent with these findings (Fig. 4). Although densities estimates vary between study areas, the composition of land-cover and protected land utilized within each area is comparatively consistent (Supplementary Tables 1 \& 2). The Langeberg's leopard pixel densities on agricultural land are higher than in the other two study areas, and equal to the Garden Route's natural vegetation (Fig. 4). This can be attributed to the predominantly non-conflict crop cultivation (vineyard and orchard) in a valley surrounded by natural mountain vegetation. Additionally, the majority $(89 \%)$ of the estimated leopard pixel density on agricultural land across all study areas occurs in cultivated commercial fields and $11 \%$ occurs in forestry plantations, which can generally be considered non-conflict agriculture.

All three areas demonstrate a discrepancy between suitable habitat and land designated as protected for the conservation and sustainability of biodiversity (Figs $4 \& 5$ ). The vast majority of each area's estimated leopard pixel density occurs on non-protected land with the highest percentage occurring in the Overberg (89\%) (Fig. 5; Supplementary Table 2).

Our secr and SPACECAP estimates are some of the lowest national density estimates for leopards and are comparable to three other studies in the Western Cape (Martins, 2010; Mann, 2014; Devens et al., 2018; Table 4). The difference between the estimates from the two programmes was greater than expected, which could be attributed partially to the extra Maxent habitat mask covariate modelling incorporated into the SPACECAP analyses. The likelihood method requires substantially less computation time than the Bayesian approach (seconds or minutes vs hours or days), is less sensitive to buffer width and data augmentation size and has greater convenience and versatility for customization with covariates and models. SPACECAP entails checks to verify that convergence is achieved, model fit is sufficient, and data augmentation is adequate. Hence, it is more appropriate and robust for small sample sizes. Our mean SPACECAP density estimate of 1.18 leopards $/ 100 \mathrm{~km}^{2}$ is directly comparable to results from Devens et al. (2018), who reported mean density estimates of 0.95 and $0.9-1.11$ leopards $/ 100 \mathrm{~km}^{2}$ for SPACECAP and two GPS methods, respectively (Table 4). The GPS methods used data from 21 collared leopards and incorporated home range size (home range density estimate) and home range overlap of same-sex neighbouring leopards (socially considerate density estimate). Therefore, we suggest our SPACECAP results are more accurate and reliable for determining the spatial requirements of species. We recommend spatially explicit capture-recapture methods for future research, with the specific incorporation of GPS collar data, because these methods are the most robust at capturing a species' spatial ecology within a population.

We extrapolated an ecological density (number of individuals per useable area) using our density estimates and a prediction of $49,850 \mathrm{~km}^{2}$ suitable leopard habitat remaining in the Western Cape (Swanepoel et al., 2013). Our findings suggest that there are 175-588 leopards remaining (Table 3). However, this may be an optimistic estimation. Habitat modelling is not infallible and identified suitable habitat is not necessarily useable for wide-ranging species such as the leopard. The available habitat estimate included fragmented 
TABLE 4 Published South African leopard population density estimates for data collected after 20oo, with the analysis programme used.

\begin{tabular}{llll}
\hline Region & Source & Density estimate (leopards/100 km ${ }^{2}$ ) & Programme $^{1}$ \\
\hline Various (Western Cape) & This study & $0.17-0.50$ (mean 0.35) & secr \\
& & $0.69-1.89$ (mean 1.18) & SPACECAP \\
Various (Western Cape, Eastern Cape) & Devens et al. (2018) & $0.24-1.89$ (mean 0.95) & HRDE \\
& & 0.90 & SCDE \\
& & 1.11 & CAPTURE \\
Little Karoo (Western Cape) & Mann (2014) & 0.50 & DENSITY \\
& & 1.18 & CAPTURE \\
Cederberg Mountains (Western Cape) & Martins (2010) & $1.80-2.30$ & CAPTURE \\
Phinda-Mkhuze Complex (Kwazulu-Natal) & Balme et al. (2010) & $2.49-11.11$ & CAPTURE \\
Zululand Rhino Reserve (Kwazulu-Natal) & Chapman \& Balme (2010) & $2.50-7.00$ & secr \\
Phinda Private Game Reserve (Kwazulu-Natal) & Braczkowski et al. (2016) & 3.40 & 3.65 \\
& & $7.28-9.28$ & SPACECAP \\
& & $4.56-6.59$ & CAPTURE \\
Waterberg Mountains (Limpopo) & Swanepoel et al. (2015) & secr \\
Phinda Private Game Reserve (Kwazulu-Natal) & Balme et al. (2009a) & 6.97 & CAPTURE \\
Phinda Private Game Reserve (Kwazulu-Natal) & Balme et al. (2009b) & $7.17-11.21$ & CAPTURE \\
Soutpansberg Mountains (Limpopo) & Chase Grey et al. (2013) & 10.70 & SPACECAP \\
N’wanetsi Concession (Kruger National Park) & Maputla et al. (2013) & 12.70 & CAPTURE \\
\hline
\end{tabular}

${ }^{1} \mathrm{HRDE}$, home range density estimate; SCDE, socially considerate density estimate.

habitat, small isolated pockets of habitat and areas of habitat subject to edge effects and anthropogenic pressures. These factors can lead to habitat areas being unable to accommodate viable populations (Woodroffe \& Ginsberg, 1998). In addition, our maximum Western Cape population estimate of 588 individuals is well below the minimum viable population size necessary to maintain genetic diversity (Traill et al., 2007). The genetic population structure of leopards in the Western Cape and Eastern Cape provinces indicates very low to moderate gene flow between the three subpopulations (McManus et al., 2015).

Although highly adaptable, the leopard is a widely persecuted species that experiences varying levels of anthropogenic threats and habitat loss. Our results suggest that protected areas are inadequate to secure the long-term conservation of leopards in the Western Cape. By establishing density and population size estimates in an increasingly fragmented and modified landscape, we increase the understanding of how leopards can persist in human-dominated areas, influencing conservation planning for the species. For adaptive and wide-ranging species such as large carnivores, non-protected and human-dominated areas are becoming increasingly important for genetic dispersal and landscape connectivity (Boron et al., 2016). The threats and conservation conflicts affecting the leopard in South Africa's Cape region are affecting all apex carnivores globally. Accurate density estimates are critically important as numerous anthropogenic interests continue to threaten leopards, their resources and habitat.

Acknowledgements We thank the ABAX Foundation, Development Bank South Africa, Green Fund, United Nations Environmental Program, Global Environmental Facility, Henry and
Iris Englund Foundation, National Lotteries Distribution Trust Fund, Mones Michaels Trust, Arne Hanson and the Deutsche Bank South Africa Foundation for assisting in funding this research. MJS was supported by the National Research Foundation. We acknowledge Landmark Foundation for providing the resources to enable this research, and thank private landowners and CapeNature for their cooperation and assistance.

Author contributions Study conception: CHD, BS, JM; methodology design, data collection and writing: CHD; data analysis: $\mathrm{CHD}$, TT; revisions: $\mathrm{MS}, \mathrm{MH}, \mathrm{AD}, \mathrm{TT}, \mathrm{BS}$.

\section{Conflicts of interest None.}

Ethical standards All authors have abided by the Oryx guidelines on ethical standards, and fieldwork was conducted with the necessary approvals and permits from appropriate institutions and statutory authorities. Cape Nature Research Permit to collect fauna specimens for scientific research in the Western Cape was granted to CHD in August 2014 (permit no.: AAA007-00130-0056) and prior cameratrap data was covered under a Cape Nature Permit for JM. These permits were granted for the purposes of collaring leopards. CHD was also granted an Animal Ethics Committee Approval Certificate from the University of Pretoria in February 2014-December 2016 (project number: EC005-14). We did not collect specimens for this study, and all fieldwork was conducted ethically with the cooperation of local conservation authorities and landowners.

\section{References}

Balme, G.A., Hunter, L.T. \& Slotow, R. (2009a) Evaluating methods for counting cryptic carnivores. Journal of Wildlife Management, 73, 433-441.

Balme, G.A., Slotow, R. \& Hunter, L.T. (2009b) Impact of conservation interventions on the dynamics and persistence of a persecuted leopard (Panthera pardus) population. Biological Conservation, 142, 2681-269o. 
Balme, G.A., Slotow, R. \& Hunter, L.T.B. (2010) Edge effects and the impact of non-protected areas in carnivore conservation: leopards in the Phinda-Mkhuze Complex, South Africa. Animal Conservation, 13, 315-323.

Borchers, D.L. \& EFFord, M.G. (2008) Spatially explicit maximum likelihood methods for capture-recapture studies. Biometrics, 64, 377-385.

Boron, V., Tzanopoulos, J., Gallo, J., Barragan, J., JaimesRodriguez, L., Schaller, G. \& Payán, E. (2016) Jaguar densities across human-dominated landscapes in Colombia: the contribution of unprotected areas to long term conservation. PLOS ONE, 11, e0153973.

Braczkowski, A.R., Balme, G.A., Dickman, A., Fattebert, J., Johnson, P., Dickerson, T. et al. (2016) Scent lure effect on camera-trap based leopard density estimates. PLOS ONE, 11, eo151033.

Cardillo, M., Purvis, A., Sechrest, W., Gittleman, J.L., Bielby, J. \& MACE, G.M. (2004) Human population density and extinction risk in the world's carnivores. PLOS Biology, 2, e197.

CapeNature (2014) 2013/2014 Western Cape Landcover Product. Vector Geospatial Dataset. Western Cape Nature Conservation Board, Bridgetown, South Africa.

Chapman, S. \& Balme, G. (2010) An estimate of leopard population density in a private reserve in KwaZulu-Natal, South Africa, using camera traps and capture-recapture models. South African Journal of Wildlife Research, 40, 114-120.

Chase Grey, J.N., Kent, V.T. \& Hill, R.A. (2013) Evidence of a high density population of harvested leopards in a montane environment. PLOS ONE, 8, 1-11.

Crooks, K.R. (2002) Relative sensitivities of mammalian carnivores to habitat fragmentation. Conservation Biology, 16, 488-502.

Department of Environmental Affairs (2017) South Africa Protected Areas Database (SAPAD_OR_2017_Q3). Http://egis. environment.gov.za [accessed 11 March 2019].

Devens, C., Tshabalala, T., McManus, J. \& Smuts, B. (2018) Counting the spots: the use of a spatially explicit capture-recapture technique and GPS data to estimate leopard (Panthera pardus) density in the Eastern and Western Cape, South Africa. African Journal of Ecology, 56, 1-10.

EFFORD, M.G. (2011) secr-spatially explicit capture-recapture in $R$. $R$ package version 2.1.o. Https://CRAN.R-project.org/package $=$ secr [accessed 11 March 2019].

EFFORD, M.G. (2016) secr: Spatially explicit capture-recapture models. $R$ package version 2.10.3. Https://CRAN.R-project.org/package=secr [accessed 11 March 2019].

EFFord, M.G. \& Fewster, R.M. (2013) Estimating population size by spatially explicit capture-recapture. Oikos, 122, 918-928.

Efford, M.G., Borchers, D.L. \& Byron, A.E. (2009) Density estimation by spatially explicit capture-recapture: likelihood-based methods. In Modeling Demographic Processes in Marked Populations (eds D.L. Thomson, E.G. Cooch \& M.J. Conroy), pp. 255-269. Springer, New York, USA.

Ellis, E.C. \& Ramankutty, N. (2008) Putting people in the map: anthropogenic biomes of the world. Frontiers in Ecology and the Environment, 6, 439-447.

Estes, J.A., Terborgh, J., Brashares, J.S., Power, M.E., Berger, J., Bond, W.J. et al. (2011) Trophic downgrading of planet Earth. Science, 333, 301-306.

FAO (Food and Agriculture Organization of the United Nations) (2012) FAO GeoNetwork. Land Cover of South Africa Globcover Regional. FAO, Rome, Italy. Http://www.fao.org/ geonetwork/srv/en/metadata.show currTab $=$ simple $\& i d=37221$ [accessed 13 June 2019].
Foster, R.J. \& Harmsen, B.J. (2012) A critique of density estimation from camera-trap data. The Journal of Wildlife Management, 76 , 224-236.

Gerber, B.D., Karpanty, S.M. \& Kelly, M.J. (2012) Evaluating the potential biases in carnivore capture-recapture studies associated with the use of lure and varying density estimation techniques using photographic-sampling data of the Malagasy civet. Population Ecology, 54, 43-54.

Gopalaswamy, A.M., Royle, J.A., Hines, J.E., Singh, P., Jathanna, D., Kumar, N.S. \& Karanth, K.U. (2012) Program SPACECAP: software for estimating animal density using spatially explicit capture-recapture models. Methods in Ecology and Evolution, $3,1067-1072$.

Griffiths, M. \& van Schaik, C.P. (1993) The impact of human traffic on the abundance and activity periods of Sumatran rain forest wildlife. Conservation Biology, 7, 623-626.

Harcourt, A., Parks, S. \& Woodroffe, R. (2001) Human density as an influence on species/area relationships: double jeopardy for small African reserves? Biodiversity \& Conservation, 10, 1011-1026.

Hayward, M.W., Boitani, L., Burrows, N.D., Funston, P., Karanth, K.U., MacKenZie, D. et al. (2015) Ecologists need to use robust survey design, sampling and analysis methods. Journal of Applied Ecology, 52, 286-290.

Hijmans, R.J., Cameron, S.E., Parra, J.L., Jones, P.G., Jarvis, A. (2005) Very high resolution interpolated climate surfaces for global land areas. International Journal of Climatology: a Journal of the Royal Meteorological Society, 25, 1965-1978.

Jacobson, A.P., Gerngross, P., Lemeris, JR, J.R., Schoonover, R.F., Anco, C., Breitenmoser-Würsten, C. et al. (2016) Leopard (Panthera pardus) status, distribution, and the research efforts across its range. PeerJ, 4, e1974.

Jenks, G.F. (1967) The data model concept in statistical mapping. International Yearbook of Cartography, 7, 186-190.

Kalle, R., Ramesh, T., Qureshi, Q. \& Sankar, K. (2011) Density of tiger and leopard in a tropical deciduous forest of Mudumalai Tiger Reserve, southern India, as estimated using photographic capturerecapture sampling. Acta Theriologica, 56, 335-342.

KarAnth, K.U. (1995) Estimating tiger (Panthera tigris) populations from camera-trap data using capture-recapture models. Biological Conservation, 71, 333-338.

Karanth, K.U. \& Chellam, R. (2009) Carnivore conservation at the crossroads. Oryx, 43, 1-2.

KARANTH, K.U. \& NiChOLS, J.D. (1998) Estimation of tiger densities in India using photographic captures and recaptures. Ecology, 79, 2852-2862.

Karanth, K.U. \& Nichols, J.D. (2000) Ecological Status and Conservation of Tigers in India. Final Technical Report to the Division of International Conservation, US Fish and Wildlife Service, Washington, DC, USA, Wildlife Conservation Society, New York, USA, and Centre for Wildlife Studies, Bangalore, India.

MANN, G. (2014) Aspects of the ecology of leopards (Panthera pardus) in the Little Karoo, South Africa. PhD thesis, Rhodes University, Grahamstown, South Africa.

Maputla, N.W., Chimimba, C.T. \& Ferreira, S.M. (2013) Calibrating a camera-trap based biased mark-recapture sampling design to survey the leopard population in the N'wanetsi concession, Kruger National Park, South Africa. African Journal of Ecology, 51, 422-430.

Martins, Q.E. (2010) The ecology of the leopard Panthera pardus in the Cederberg Mountains. PhD thesis, University of Bristol, Bristol, UK.

McManus, J., Dickman, A., Gaynor, D., Smuts, B. \& Macdonald, D. (2014) Dead or alive? Comparing costs and 
benefits of lethal and non-lethal human-wildlife conflict mitigation on livestock farms. Oryx, 49, 687-695.

McManus, J., Dalton, D.L., Kotzé, A., Smuts, B. \& Dickman, A. (2015) Gene flow and population structure of a solitary top carnivore in a human-dominated landscape. Ecology and Evolution, 5, 335-344.

Mucina, L. \& Rutherford, M.C. (eds) (2006) The Vegetation of South Africa, Lesotho and Swaziland. South African National Biodiversity Institute, Pretoria, South Africa.

Noss, A.J., Gardener, B., Maffei, L., Cuéllar, E., Montaño, R. et al. (2012) Comparison of density estimation methods for mammal populations with camera traps in the Kaa-lya del Gran Chaco landscape. Animal Conservation, 15, 527-535.

Obbard, M.E., Howe, E.J. \& Kyle, C.J. (2010) Empirical comparison of density estimators for large carnivores. Journal of Applied Ecology, 47, 76-84.

Phillips, S.J., Dudik, M., Schapire, R.E. (2017) Maxent Software for Modelling Species Niches and Distributions (version 3.4.1). Http://biodiversityinformatics.amnh.org/open_source/maxent [accessed 23 July 2019].

Phillips, S.J., Anderson, R.P. \& Schapire, R.E. (2006) Maximum entropy modeling of species geographic distributions. Ecological Modelling, 190, 231-259.

QGIS Development Team (2013) QGIS Geographic Information System. Open Source Geospatial Foundation, Beaverton, USA. Http://qgis.osgeo.org [accessed 11 March 2019].

R Core Team (2017) R: a Language and Environment for Statistical Computing. $R$ Foundation for Statistical Computing, Vienna, Austria. Http://www.R-project.org [accessed 23 July 2019].

Ray, J.C., Hunter, L.T.B. \& Zigouris, J. (2005) Setting Conservation and Research Priorities for Larger African Carnivores. Wildlife Conservation Society, New York, USA.

Rouget, M., Reyers, B., Jonas, Z., Desmet, P., Driver, A., Maze, K. et al. (2004) South African National Spatial Biodiversity Assessment 2004: Technical Report. Volume 1: Terrestrial Component. South African National Biodiversity Institute, Pretoria, South Africa.

Ripple, W.J., Estes, J.A., Beschta, R.L., Wilmers, C.C., Ritchie, E.G., Hebblewhite, M. et al. (2014) Status and ecological effects of the world's largest carnivores. Science, 343, 1241484.

R S tudio Team (2015) R Studio: Integrated Development for $R$. RStudio, Inc., Boston, USA. Http://www.rstudio.com [accessed 11 March 2019].

Silver, S.C., Ostro, L.E.T., Marsh, L.K., Maffei, L., Noss, A.J., Kelly, M.J. et al. (2004) The use of camera traps for estimating jaguar Panthera onca abundance and density using capture/ recapture analysis. Oryx, 38, 148-154.
Soisalo, M.K. \& CavalCanti, S.M.C. (2006) Estimating the density of a jaguar population in the Brazilian Pantanal using camera traps and capture-recapture sampling in combination with GPS radio-telemetry. Biological Conservation, 129, 487-496.

Swanepoel, L.H., Lindsey, P., Somers, M.J., Hoven, W.V. \& Dalerum, F. (2013) Extent and fragmentation of suitable leopard habitat in South Africa. Animal Conservation, 16, 41-50.

Swanepoel, L.H., Somers, M.J. \& Dalerum, F. (2015) Density of leopards Panthera pardus on protected and non-protected land in the Waterberg Biosphere, South Africa. Wildlife Biology, 21, 263-268.

Thamm, A.G. \& Johnson, M.R. (2006) The Cape Supergroup. In The Geology of South Africa (eds M.R. Johnson, C.R. Anhaeusser \& R.J. Thomas), pp. 443-46o. Geological Society of South Africa, Johannesburg/Council for Geoscience, Pretoria, South Africa.

Thapa, K., Shrestha, R., Karki, J., Thapa, G.J., Subedi, N., Pradhan, N.M.B. et al. (2014) Leopard Panthera pardus fusca density in the seasonally dry, subtropical forest in the Bhabhar of Terai Arc, Nepal. Advances in Ecology, 2014, 1-12.

Treves, A. \& Karanth, K.U. (2003) Human-carnivore conflict and perspectives on carnivore management worldwide. Conservation Biology, 17, 1491-1499.

Treves, A. \& Naughton-Treves, L. (2005) Evaluating lethal control in the management of human-wildlife conflict. Conservation Biology, 9, 86-106.

Treves, A., Naughton-Treves, L., Harper, E.K., Mladenoff, D.J., Rose, R.A., Sickley, T.A. \& Wydeven, A.P. (2004) Predicting human-carnivore conflict: a spatial model derived from 25 years of data on wolf predation on livestock. Conservation Biology, 18, 114-125.

Traill, L.W., Bradshaw, C.J.A. \& Brook, B.W. (2007) Minimum viable population size: a meta-analysis of 30 years of published estimates. Biological Conservation, 139, 159-166.

WCS (Wildlife Conservation Society) \& CiESin (Center for International Earth Science Information Network) (2005) Last of the Wild Project, Version 2, 2005 (LWP-2): Global Human Footprint Dataset (Geographic). NASA Socioeconomic Data and Applications Center, Palisades, USA. Https://doi.org/10.7927/ $\mathrm{H}_{4} \mathrm{M}_{61} \mathrm{H}_{5} \mathrm{~F}$ [accessed 13 June 2019].

Wolf, C. \& Ripple, W.J. (2017) Range contractions of the world's large carnivores. Royal Society Open Science, 4, 170052.

Woodroffe, R. (200o) Predators and people: using human densities to interpret declines of large carnivores. Animal Conservation, 3 , 165-173.

Woodroffe, R. \& Ginsberg, J.R. (1998) Edge effects and the extinction of populations inside protected areas. Science, 280, 2126-2128. 